\title{
Effects of pyrolytic and petrogenic polycyclic aromatic hydrocarbons on swimming and metabolic performance of zebrafish contaminated by ingestion
}

\author{
Lucas Julie ${ }^{1,2,{ }^{*}}$, Percelay Isabelle ${ }^{1}$, Larcher T. ${ }^{3}$, Lefrancois C. ${ }^{1}$
}

1 Inst Littoral \& Environm, UMR Littoral Environm Soc LIENSs 7266, 2 Rue Olympe de Gouges, F-

17000 La Rochelle, France.

2 IFREMER, PI Gaby Coll,BP7, F-17137 Lhoumeau, France.

${ }^{3}$ Oniris, APEX, INRA UMR 703, F-44300 Nantes, France.

*Corresponding author : Julie Lucas, email address : julie.lucas@laposte.net

\begin{abstract}
:
Depending on their origins, polycyclic aromatic hydrocarbons (PAH) are characterized by different chemical properties. Petrogenic PAH (e.g. from fossil fuels) and pyrolytic PAH (e.g. those produced by incineration processes) are therefore expected to affect organisms differently. The impact of trophic exposure to these $\mathrm{PAH}$ was investigated on swimming and metabolic performance of zebrafish Danio rerio. Two-month-old juveniles and six-month-old adults were individually challenged following a swimming step protocol. While pyrolytic exposure did not affect fish whatever the duration of exposure, it appeared that petrogenic PAH impaired adults' performance. Indeed, the active metabolic rate in petrogenic $\mathrm{PAH}$-contaminated adults was significantly reduced by $35 \%$, and critical swimming speed by $26.5 \%$. This was associated with cardiac abnormalities, which are expected to contribute to the reduction of oxygen transport, particularly during intensive effort. These results may be due to the different composition and toxicity of PAH mixtures.
\end{abstract}

\section{Highlights}

Toxicity of pyrolytic and petrogenic PAH mixes were tested on zebrafish. Contamination occurred by ingestion. P Petrogenic PAH directly impaired fish swimming performance. Pyrolytic PAH seems to impair the progeny of contaminated fish.

Keywords : Trophic exposition, Petroleum hydrocarbons, Critical swimming speed, Aerobic metabolic rate, Sub-lethal concentration 


\section{Introduction}

Locomotion performance in fish is considered to be a relevant biological function contributing to survival (e.g. Graham et al., 1990; Jones et al., 1974; Plaut, 2001; Stobutzki and Bellwood, 1994; Swanson et al., 1998), since it is related to predator-prey interactions, food research and migration (Drucker and Jensen, 1996; Hammer, 1995; Plaut, 2001; Reidy et al., 1995; Videler, 1993; Walker et al., 2005; Watkins, 1996;). Critical swimming speed (i.e. the maximal velocity a fish can reach during a swimming step protocol, $\mathrm{U}_{\text {crit }}$; Hammer, 1995) is frequently employed as an indicator of swimming capacities in a varying environment (e.g. Beamish, 1978). Since $U_{\text {crit }}$ notably depends on the maximal ability of fish to provide energy during sustained swimming activity, these studies are often associated with the assessment of metabolic performance, which contribute to a better view of the environmental impact. Aerobic metabolic scope (AMS; Brett, 1964; Fry, 1947, 1971) is defined as the difference between (i) the active metabolic rate (AMR), which is the highest metabolic rate the organism can sustain under maximal activity and (ii) the standard metabolic rate (SMR), the metabolic rate necessary to maintain vital functions and measured under resting conditions. Metabolic and swimming performance are known to be modulated by a set of environmental parameters, such as temperature (Blier et al., 1997; Farrell, 2007; Rome et al., 2007), dissolved oxygen (Diaz, 2001; Diaz et al., 2004) or pollutants (Johansen and Jones, 2011; Lefrançois and Claireaux, 2003; Marit and Weber, 2012; Shingles et al., 2001; Schurmann and Steffensen, 1997; Thomas et al., 2013).

This study aimed at investigating responses of fish exposed to environmentally relevant concentrations of PAH through the assessment of AMS and $\mathrm{U}_{\text {crit }}$ as indicators of the physiological state of the organism (Fry, 1947). The increase of anthropogenic activities in coastal areas induces discharges of $\mathrm{PAH}$ in aquatic ecosystems. Due to their high 
liposolubility, PAH are typically adsorbed by organic matter or marine sediments, bioaccumulated by organisms at the lowest trophic levels (e.g. invertebrates; Bustamante et al., 2012; O'Connor and Lauenstein, 2006) and transferred through trophic chains (Hylland, 2006; Vignet et al., 2014). Past studies on fish have demonstrated that hydrocarbon exposure causes a decrease of $U_{\text {crit }}$. For instance, Danio rerio showed a $15 \%$ and $22 \%$ reduction of $U_{\text {crit }}$ while exposed to crude oil (Hicken et al., 2011) and TCDD (2,3,7,8-tetrachlorodibenzo-p-dioxin; Marit and Weber, 2012), respectively. Moreover, PAH could induce damage of tissues and/or organs involved in oxygen transport (e.g. fish gills, Fasulo et al., 2012; mussel gills, Cappello et al., 2013). This could induce a decrease of AMR as observed by Davoodi and Claireaux (2007) after acute PAH exposure of Solea solea. In addition, the implementation of detoxification processes which are energy costly have already been demonstrated. These processes are likely to increase costs of maintenance and, consequently, SMR. The consequent potential reduction of AMS would reflect a decrease in the capacity of fish to sustain energy-demanding activities.

The effects of PAH mixtures were tested on zebrafish Danio rerio (F. Hamilton, 1822) contaminated by ingestion. Both pyrolytic PAH (PY-PAH, resulting from the combustion of organic matter) and petrogenic PAH (HO-PAH, originated from fossil fuels; Hylland, 2006) were considered in the present study. Present as complex mixtures in the environment, PYPAH and HO-PAH show different chemical properties and may induce various effects on aquatic life. The main hypothesis was that chronic exposure to PY-PAH and HO-PAH would impair AMS by increasing SMR and/or reducing AMR. The consequent potential reduction of AMS would indicate a decrease in the capacity of the fish to support oxygen-demanding activities beyond SMR and consequently a reduction of $\mathrm{U}_{\text {crit. }}$ In addition, PAH may induce anatomic impairments due to teratogenic effects (Hawkins et al., 1990; Myers et al., 1991). Swimming and metabolic functions were explored, as well as the cardiac and skeletal muscle 
structures, as two key tissues involved the tested functions.

\section{Materials and methods}

\subsection{General production of zebrafish}

Pairs of zebrafish (wild-type Tuebingen strain, TU) were reared together in $10 \mathrm{~L}$ tanks in the laboratory. Aquaria were filled with a mix of osmosis and filtered tap water which was characterized by the following parameters: temperature $28 \pm 0.5^{\circ} \mathrm{C}$, conductivity $300 \pm 50$ $\mu \mathrm{S} . \mathrm{cm}^{-1}$, oxygen saturation $\geq 80 \%, \mathrm{pH} 7.5 \pm 0.5$. Fish were reared with a photoperiod of $14 \mathrm{~h}$ light/10 h dark. Ammonia, nitrite and nitrate remained within recommended ranges (Lawrence, 2007). The fish were fed twice daily with uncontaminated commercial dry food (INICIO Plus, BioMar, France) and once by Artemia sp. nauplii (Ocean Nutrition, Belgium), occasionally supplemented with red sludge worms (Boschetto, Poland).

Over a period of one month, spawn was obtained from pairs weekly following the protocol described in Lucas et al. (2014a) and Vignet et al. (2014). Briefly, the day before spawn was collected, these fish couples were isolated in $1 \mathrm{~L}$ breeding tanks (Aqua Schwarz, Germany). After collection, fertilized and normally developed eggs were selected using a binocular microscope. Spawn was then mixed to avoid any parental influence. From 2 weeks onwards, fish were kept in groups of 30 individuals in $10 \mathrm{~L}$ aquaria in the same specific rearing system described above.

\subsection{Food contamination protocol}


119 described in detail by Vignet et al. (2014). Briefly, the pyrolytic fraction $(P Y)$ was extracted

120 from natural sediment sampled at the site of Oissel (Seine Bay, France), while the petrogenic

121 fraction $(H O)$ was extracted from heavy Erika fuel oil. For both types of $P Y$ and $H O$ mixtures,

122 quantification of the 16 individual PAH of the US EPA list was made, according to a protocol

123 described in Budzinski et al. (1997) and Cachot et al. (2007). The food was then spiked with

124 the extracted $P Y$ or $H O$ fractions according to a protocol adapted from Vicquelin et al. (2011).

125 The target concentration was $15000 \mathrm{ng} \cdot \mathrm{g}^{-1}$ of food and based on the sum of the 16 PAH from

126 the US EPA list in dry weight. This corresponds to three times the PAH concentration

127 organisms may be exposed to in their natural environment (Cachot et al., 2006; Cailleaud et

128 al., 2007; Payne et al., 2008). This high concentration was used to highlight the toxicological

129 effects on the physiological performances investigated in this study. It is called $X$ in the rest of

130 the manuscript. Food size was adapted to the developmental stage of D. rerio. A control

131 treatment was also considered, and consisted of feeding groups of fish with uncontaminated

132 food, treated only by the solvent dichloromethane. This solvent was used to improve PAH

133 incorporation into the food, and then evaporated. PAH compositions and concentrations in the

134 diet are described in detail in Table 1.

135 
Table 1. Concentration of 21 US-EPA PAH in contaminated dry food. Values are expressed as mean \pm standard deviation. n.d. $=$ not detected

\begin{tabular}{|c|c|c|c|c|c|}
\hline \multirow[b]{3}{*}{ PAHs } & \multirow[b]{3}{*}{$\begin{array}{c}\text { Molecular weight } \\
(\text { g.mol }\end{array}$} & \multicolumn{4}{|c|}{ Concentration in dry food (ng.g-l) } \\
\hline & & \multicolumn{2}{|c|}{ pyrolytic PAH } & \multicolumn{2}{|c|}{ petrogenic $\mathrm{PAH}$} \\
\hline & & Solvent & $3 \mathrm{x}$ & Solvent & $3 \mathrm{x}$ \\
\hline Naphtalene & 128.2 & $4.01 \pm 2.21$ & $199.13 \pm 32.06$ & $3.79 \pm 0.97$ & $405.02 \pm 73.41$ \\
\hline Acenaphthylene & 152.2 & $0.87 \pm 0.26$ & $124.82 \pm 12.38$ & $1.31 \pm 0.51$ & $13.10 \pm 12.77$ \\
\hline Acenaphtene & 154.2 & $1.91 \pm 0.64$ & $99.49 \pm 10.80$ & $27.29 \pm 26.07$ & $190.11 \pm 17.26$ \\
\hline Fluorene & 166.2 & $2.62 \pm 0.48$ & $148.22 \pm 18.02$ & $2.34 \pm 1.05$ & $312.01 \pm 25.07$ \\
\hline Dibenzothiophenes & 184.26 & $0.68 \pm 0.46$ & $117.95 \pm 10.61$ & $0.34 \pm 0.16$ & $545.94 \pm 53.56$ \\
\hline Phenanthrene & 178.2 & $9.36 \pm 3.73$ & $1029.78 \pm 88.76$ & $6.11 \pm 2.73$ & $1278.88 \pm 51.23$ \\
\hline Antracene & 178.2 & $0.78 \pm 0.31$ & $598.14 \pm 53.81$ & $0.37 \pm 0.22$ & $219.76 \pm 9.75$ \\
\hline Fluoranthenes & 202.3 & $1.37 \pm 0.39$ & $1968 \pm 179.78$ & $1.92 \pm 0.71$ & $145.08 \pm 17.70$ \\
\hline Pyrenes & 202.3 & $1.62 \pm 0.21$ & $1648.54 \pm 179.45$ & $1.45 \pm 0.27$ & $709.13 \pm 64.10$ \\
\hline Benzo[a]anthracene & 228.3 & $0.76 \pm 0.26$ & $2286.28 \pm 200.96$ & n.d. & $542.78 \pm 29.08$ \\
\hline Chrysene+Triphenylene & 228.3 & $0.77 \pm 0.26$ & $2984.46 \pm 240.64$ & n.d. & $1073.29 \pm 78.69$ \\
\hline Benzonaphthothiophene & 252,3 & $6.53 \pm 0.73$ & $660.11 \pm 56.98$ & n.d. & $572.96 \pm 35.67$ \\
\hline Benzo $[b, k, j]$ fluoranthenes & 252.3 & $1.54 \pm 0.56$ & $3164.65 \pm 269.51$ & n.d. & $362.75 \pm 17.62$ \\
\hline Benzo[e]pyrene & 252.3 & $0.89 \pm 0.37$ & $1267.09 \pm 108.51$ & n.d. & $535.54 \pm 25.67$ \\
\hline Benzo[a]pyrene & 252.3 & $0.72 \pm 0.55$ & $1395.49 \pm 146.63$ & n.d. & $342.12 \pm 10.42$ \\
\hline Perylene & 252.3 & $0.96 \pm 0.48$ & $437.37 \pm 39.40$ & n.d. & $172.01 \pm 13.89$ \\
\hline Indeno $[1,2,3$-cd $]$ pyrene & 276.3 & n.d. & $1218.26 \pm 123.95$ & n.d. & $68.42 \pm 10.88$ \\
\hline Dibenzo[a]anthracene + Dibenzo[a]chrysene & 276.3 & $2.22 \pm 1.74$ & $369.38 \pm 53.74$ & n.d. & $112.55 \pm 6.26$ \\
\hline Benzo[g,h,i]perylene & 276.3 & n.d. & $913.77 \pm 88.29$ & n.d. & $480.53 \pm 12.21$ \\
\hline Sum PAHs & & $34 \pm 6$ & $17305 \pm 4798$ & $39 \pm 30$ & $8082.5 \pm 305$ \\
\hline
\end{tabular}

\subsection{Zebrafish PAH exposure protocol}

140 Contamination through food was conducted by feeding zebrafish larvae twice a day with one

141 of the treatments (i.e. control and $X$ for both types of contamination $P Y$ and $H O$ ). The diet

142 started from the first meal (5 days post fertilization, dpf) until the age at the test: 2 months and

1436 months for juveniles and adults, respectively. In accordance with the protocols in Vignet et

144 al. (2014), larvae were fed ad libitum and then, starting from 2 months old, the ration of food

145 was decreased by $5 \%$ to $2 \%$ of the biomass in each tank in order to maintain constant growth.

146 For all fish, brine shrimp were distributed as complementary food once a day.

$147 P Y$ exposure took place during the second semester of 2011 and $H O$ exposure was carried out

148 in summer 2013. Quantification of hydroxylated metabolites in larvae at $15 \mathrm{dpf}$ indicated a

149 dose-dependent increase of metabolites, confirming successful contamination (total 
150

151275 ng.g ${ }^{-1}$; Vignet et al., 2014).

152 For the $X$ treatment tested, the average concentrations found were $136 \mathrm{ng} . \mathrm{g}^{-1}$ for $P Y$ larvae

153 and $42 \mathrm{ng}^{-\mathrm{g}^{-1}}$ for $H O$ larvae, while it was 2 or $4 \mathrm{ng} \cdot \mathrm{g}^{-1}$ in the $P Y$ and $H O$ control fish,

154 respectively (Vignet et al., 2014). It appears that PAH concentration is higher for $P Y$ than for 155 HO.

156

157

158

159

160 For both types of contamination (i.e. $P Y$ - and $H O-P A H$ ), two identical $170 \mathrm{~mL}$ swimming

161 respirometers (Loligo Systems, Denmark) were used to assess the swimming and metabolic performance of fish. Each swimming respirometer was composed of (a) a swimming chamber,

163 where the fish was placed to be tested, (b) a motor fitted with a three-bladed propeller to

164 control water flow and (c) honeycomb placed at each side of the swimming chamber to

165 laminarize the water flow. Each swimming respirometer was submerged in a 20 L buffer tank,

166 and filled with temperature-controlled (i.e. $28{ }^{\circ} \mathrm{C}$ ) and oxygenated mixed water as in the

167 rearing system. The oxygen consumption $\left(\mathrm{MO}_{2}\right.$ in $\left.\mathrm{mg} \mathrm{O}_{2} \cdot \mathrm{g}^{-1} \cdot \mathrm{h}^{-1}\right)$ associated with the activity

168 of fish was measured by intermittent-flow respirometry (Steffensen, 1989). Water supply in

169 each swimming respirometer was provided by flush pumps, which controlled water flow from

170 the buffer tank to the swimming respirometer. This allowed alternation between phases of

171 oxygen renewal and phases of $\mathrm{MO}_{2}$ measurement with a cycle of 5:20 min. In addition, a

172 peristaltic pump was used to create a continuous water flow from the respirometer to the

173 oxygen probe (flow through an oxygen minisensor, PreSens, Germany). The probe was

174 connected to an oxymeter (Microx, PreSens, Germany) to record the level of dissolved 
oxygen in the water every $5 \mathrm{~s}$. The probe was calibrated once at the beginning of the swim test using $0 \%$ and $100 \%$ air saturation for a controlled temperature of $28{ }^{\circ} \mathrm{C}$.

\subsubsection{Experimental protocol}

The fish were starved $24 \mathrm{~h}$ before being transferred individually to a swimming respirometer. They were then individually submitted to a swimming challenge. Each experimental trial consisted of challenging two fish in parallel exposed to one of three treatments: (i) fish fed by the control food and (ii) fish exposed to $P Y$ - or $H O-\mathrm{PAH}$. Each individual was submitted to a short acclimation swimming period ( $5 \mathrm{~min})$ during which the velocity was increased to 2 body lengths per second (BL. ${ }^{-1}$ ). Then, fish were left undisturbed with a water flow of 0.5 BL. $\mathrm{s}^{-1}$ for $2 \mathrm{~h}$ to permit recovery from handling stress. The swimming challenge started by increasing water flow by steps of $1.5 \mathrm{BL} . \mathrm{s}^{-1}$ from 0.5 to $6.5 \mathrm{BL} . \mathrm{s}^{-1}$ and steps of $0.75 \mathrm{BL} . \mathrm{s}^{-1}$ to the end of the test. Each step lasted 20 min, during which fish $\mathrm{MO}_{2}$ was measured. The experiment stopped when the fish fatigued, i.e. when it did not manage to swim against the current and stay on the honeycomb. Speed was then decreased to $0.5 \mathrm{BL} . \mathrm{s}^{-1}$ for a recovery period of $1.5 \mathrm{~h}$. Fish were then removed from the swimming respirometer and anaesthetized using benzocaine $\left(50 \mathrm{mg} . \mathrm{L}^{-1}\right)$. Standard and total length, mass and sex of each individual were determined; characteristics of the fish tested in the swim tunnel are described in Table 2. Before and after each trial, a blank measurement was performed to quantify microbial oxygen consumption in the swimming respirometer. The average of these two values was subtracted from the measured oxygen consumption. Each fish was tested once. 
Table 2. Biometry of fish for each PAHs fractions tested (Mean \pm SE). SL represents standard length and TL total length

\begin{tabular}{|c|c|c|c|c|c|c|}
\hline & Treatment & Lifestage & Fish & Weight (g) & $\mathrm{SL}(\mathrm{cm})$ & TL (cm) \\
\hline \multirow{4}{*}{ 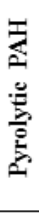 } & \multirow{2}{*}{ Control } & & $\mathrm{n}=21$ & $0.19 \pm 0.06$ & $2.20 \pm 0.19$ & $2.68 \pm 0.35$ \\
\hline & & adults & $\mathrm{n}=16$ & $0.68 \pm 0.21$ & $3.13 \pm 0.25$ & $3.88 \pm 0.35$ \\
\hline & \multirow{2}{*}{$3 X$} & & $\mathrm{n}=22$ & $0.17 \pm 0.05$ & $2.10 \pm 0.26$ & $2.59 \pm 0.26$ \\
\hline & & adults & $\mathrm{n}=15$ & $0.48 \pm 0.13$ & $2.81 \pm 0.24$ & $3.50 \pm 0.22$ \\
\hline \multirow{4}{*}{ 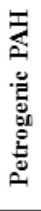 } & \multirow{2}{*}{ Control } & juveniles & $\mathrm{n}=15$ & $0.09 \pm 0.03$ & $1.82 \pm 0.28$ & $2.26 \pm 0.34$ \\
\hline & & adults & $\mathrm{n}=19$ & $0.30 \pm 0.06$ & $2.62 \pm 0.19$ & $3.29 \pm 0.23$ \\
\hline & \multirow{2}{*}{$3 x$} & juveniles & $\mathrm{n}=12$ & $0.07 \pm 0.03$ & $1.55 \pm 0.26$ & $1.97 \pm 0.29$ \\
\hline & & adults & $\mathrm{n}=11$ & $0.12 \pm 0.04$ & $1.79 \pm 0.33$ & $2.27 \pm 0.32$ \\
\hline
\end{tabular}

199 The critical swimming speed $U_{\text {crit }}$ was calculated according to the formula of Brett (1964):

203 Where $\mathrm{U}_{\mathrm{t}}\left(\right.$ in BL.s ${ }^{-1}$ ) is the highest velocity maintained for an entire step, $\mathrm{t}_{1}$ (in min) is the 204 time spent until the exhaustion of fish at the last step, $\mathrm{t}$ (in min) is the swimming period for 205 each step (i.e. $20 \mathrm{~min}$ in the present study) and $\mathrm{U}_{1}$ is the increment velocity $(0.75$ or 1.5 BL.s $\left.{ }^{-1}\right)$.

209 Oxygen consumption $\mathrm{MO}_{2}$ is expressed in $\mathrm{mg} \mathrm{O}_{2} \cdot \mathrm{g}^{-1} \cdot \mathrm{h}^{-1}$ and calculated using the following 
formula:

$212 \quad \mathrm{MO}_{2 \text { meas }}=\Delta\left[\mathrm{O}_{2}\right] \cdot \mathrm{V} \cdot \Delta \mathrm{t}^{-1} \cdot \mathrm{M}_{\text {meas }}{ }^{-1}$

Equation (2)

214 where $\Delta\left[\mathrm{O}_{2}\right]$ (in $\mathrm{mg} \mathrm{O}_{2} \cdot \mathrm{L}^{-1}$ ) is the variation in oxygen concentration during the measurement 215 period $\Delta \mathrm{t}$ (in $\mathrm{h}$ ), $\mathrm{V}$ (in $\mathrm{L}$ ) is the volume of the respirometer minus the volume of the fish and $216 \mathbf{M}_{\text {meas }}($ in $\mathrm{g}$ ) is the fish mass measured.

217 An allometric relationship exists between oxygen consumption and body mass, which permits 218 correction of $\mathrm{MO}_{2 \text { meas }}$ using the following formula:

where $\mathrm{MO}_{2 \text { cor }}$ (in $\mathrm{mg} \mathrm{O} \mathrm{O}_{2} \cdot \mathrm{g}^{-1} \cdot \mathrm{h}^{-1}$ ) is the oxygen consumption related to a standard fish of $1 \mathrm{~g}$ $\left(\mathrm{M}_{\text {cor }}\right), \mathrm{MO}_{2 \text { meas }}$ (in $\mathrm{mg} \mathrm{O}_{2} \cdot \mathrm{g}^{-1} \cdot \mathrm{h}^{-1}$ ) is the oxygen consumption estimated for experimental fish whose mass was $\mathrm{M}_{\text {meas }}$ (in $\mathrm{g}$ ) and $\mathrm{b}$ is the allometric scaling exponent describing the relationship between oxygen consumption and body mass. A previous study of Lucas et al. (2014a) estimated b in zebrafish D. rerio from the relationship between AMR and body mass, i.e. $b_{\mathrm{AMR}}$, and from the relationship between $\mathrm{SMR}$ and body mass, i.e. $\mathrm{b}_{\mathrm{SMR}}$. We used $\mathrm{b}_{\mathrm{AMR}}=$ 0.926 for the correction of AMR and $b_{\mathrm{SMR}}=0.965$ for the correction of SMR.

\subsubsection{Standard metabolic rate, active metabolic rate and aerobic metabolic scope}

231 Oxygen consumption is known to increase exponentially with swimming speed (Brett, 1964).

232 The following equation can be therefore fitted on data and allows the assessment of SMR:

$234 \quad \mathrm{MO}_{2}=\mathrm{SMR} \cdot \exp ^{\mathrm{bU}}$

Equation (4) 
236 where $\mathrm{MO}_{2}$ is the oxygen consumption (in $\mathrm{mg} \mathrm{O} \cdot \mathrm{g} \cdot{ }^{-1} \cdot \mathrm{h}^{-1}$ ), SMR is the intercept (i.e. the $\mathrm{MO}_{2}$ 237 when $\mathrm{U}=0$ BL. $\mathrm{s}^{-1}$ ), $\mathrm{b}$ is a constant and $\mathrm{U}$ is the swimming speed (in BL. ${ }^{-1}$ ).

238 AMR is evaluated as the maximum oxygen consumption measured during the swimming 239 challenge. AMS is the difference between AMR and SMR. $\mathrm{U}_{\text {crit }}, \mathrm{SMR}$, AMR and AMS were 240 assessed for each fish except for HO-PAH-exposed juveniles. No SMR data were indeed 241 recorded for these individuals, because of the small size of the fish (relative to the swim 242 tunnel volume) and the low quality of the oxygen signal. The HO exposure impaired the 243 growth of fish exposed to (Vignet et al. 2014) and consequently HO-PAH-exposed juveniles 244 were smaller than PY-PAH-exposed juveniles (Table 2).

\subsection{Histological analysis}

Analysis occurred after the swimming challenge, in older fish: 3-month-old juveniles for both types of contamination, 9-month-old adults for $P Y$-PAH and 7-month-old adults for $H O$-PAH. A total of 20 juveniles per treatment (i.e. control and $X$ ) were analysed for $P Y$ - and $H O$-PAH exposure. In adults, 30 fish per treatment were observed for $P Y$-PAH, and 25 fish were observed for HO-PAH. Fish were euthanized with a lethal dose of benzocaine $\left(100 \mathrm{mg} . \mathrm{l}^{-1}\right.$; Sigma-Aldrich), fixed in $4 \%$ formalin for 2 weeks, dehydrated and embedded in paraffin wax (Daouk et al., 2011). For each fish, 4 serial $4 \mu \mathrm{m}$-thick sections spaced from from about 250 $\mu \mathrm{m}$, were routinely stained with haematoxylin-eosin-saffron (HES). The histological appearance of cardiac and skeletal muscles of fish was then observed using a a bright-field microscope (Nikon Eclipse 90i, Champigny, France) equipped with $2 \mathrm{X}, 4 \mathrm{X}, 10 \mathrm{X}, 20 \mathrm{X}$ and 40X objectives and a SPOT digital camera (AZ microscope, London, UK). Lesions were systematically recorded by a skilled veterinary pathologist (member of the the European 


\subsection{Statistical analysis}

262 Statistical analysis was carried out using GraphPad Prism software. For AMR, SMR, AMS 263 and $\mathrm{U}_{\text {crit, }}$, normality and homoscedasticity were checked using Kolmogorov-Smirnoff and 264 Bartlett tests, respectively, for each duration of exposure and for each type of contamination 265 (i.e. $P Y$ and $H O$ ). Student's t-tests were used to compare individuals exposed to the control 266 treatment with individuals exposed to PAH. Chi-square tests were used to compare 267 histological anomalies (i.e. cardiac and skeletal muscle structures) between control fish and 268 those exposed to $P Y$-PAH or $H O-\mathrm{PAH}$. For all tests, the results were considered to be 269 significantly different when $p<0.05$.

270

\section{Results}

275 Whatever the duration of exposure, no significant difference was found between fish exposed 276 to control or PY-PAH (Student's t-test, degrees of freedom (dof) $=41$ and $\mathrm{p}=0.34$ for 277 juveniles; dof $=26$ and $p=0.40$ for adults; Fig. 1A). On the contrary, $U_{\text {crit }}$ decreased 278 significantly in both $\mathrm{HO}-\mathrm{PAH}-$ contaminated juveniles and adults compared to control279 exposed individuals (Student's t-test: dof $=24$ and $\mathrm{p}=0.011$, dof $=28$ and $\mathrm{p}=0.01$, 280 respectively; Fig. 1B). 

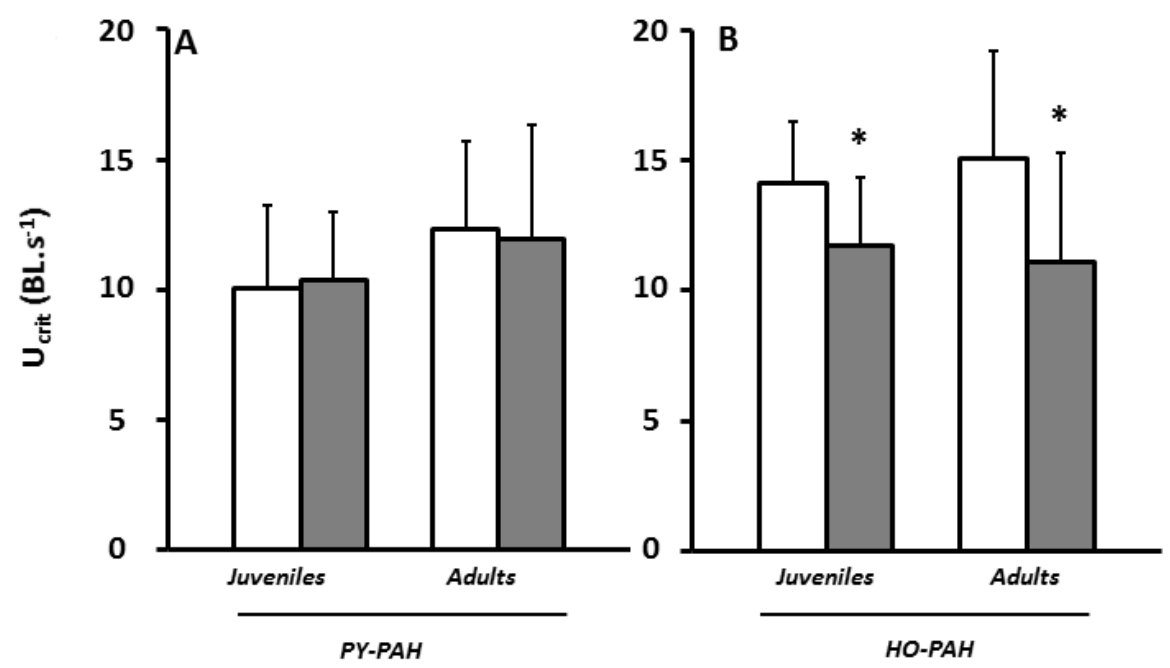

Fig. 1 Critical swimming speed $\left(U_{\text {crit }}\right)$ of zebrafish exposed to control (white bars) or to PAHs from pyrolytic (A) or petrogenic (B) origins (in grey). PAHs concentrations in food was $3 X$; the environmental reference concentrations $X$ corresponding $X p y=17305 \pm 4798 \mu{\mathrm{g} . \mathrm{g}^{-1} \text { and }}^{-1}$ Xpe $=8082.5 \pm 305 \mu \mathrm{g} \cdot \mathrm{g}^{-1}$ of dry food (table 1). $U_{\text {crit }}$ was evaluated in juvenile and adults. Results are expressed as mean values \pm standard deviation. For a given type of PAHs (PY or HO) and a given duration, * indicates a significant difference in $U_{\text {crit }}$ between control and $3 X$ treatment.

\subsection{Aerobic metabolic scope, standard and active metabolic rate}

For $P Y$-PAH contamination, no significant difference was found between contaminated fish and the control whatever the metabolic rate observed: SMR (Fig. 2A; Student's t-test: dof = 32 and $p=0.40$, dof $=26$ and $p=0.46$, for juveniles and adults, respectively), AMR (Fig. 2A; Student's t-test: dof $=34$ and $p=0.29$, dof $=26$ and $p=0.44$ for juveniles and adults, respectively) and AMS (Student's t-test: dof $=34$ and $p=0.29$, dof $=26$ and $p=0.44$ for 298 juveniles and adults, respectively). 

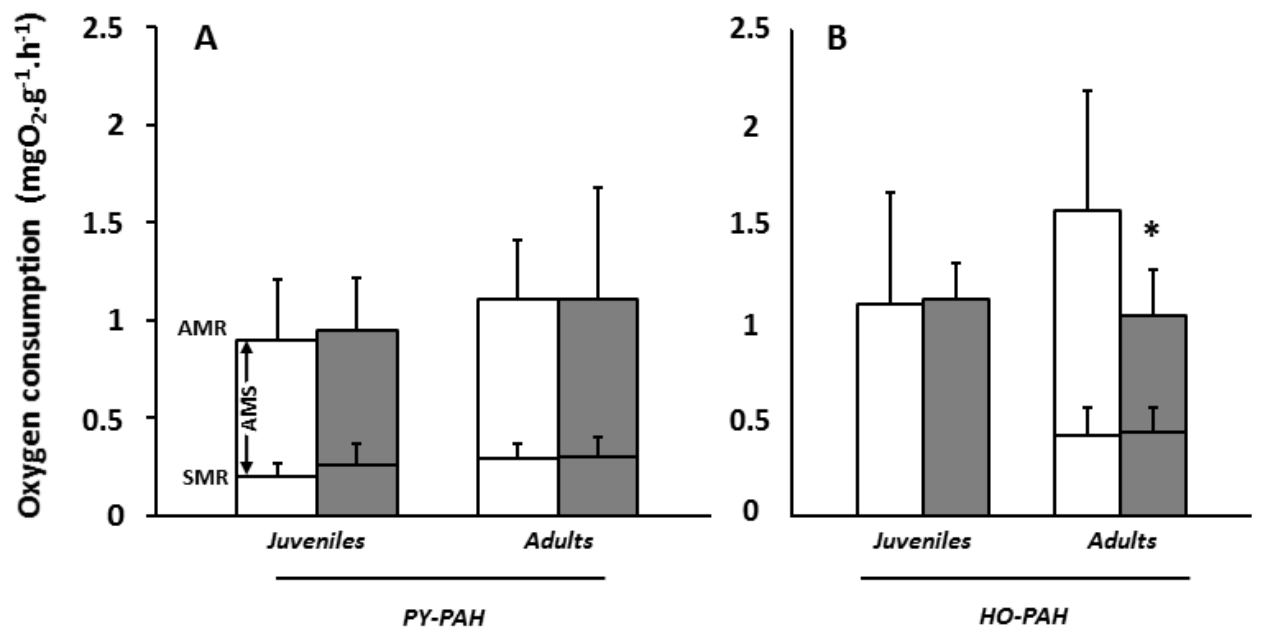

Fig. 2. Standard metabolic rate (SMR), active metabolic rate (AMR) and aerobic metabolic scope (AMS) of zebrafish Danio rerio exposed to control food (white bars) containing, pyrolytic (A) or petrogenic (B) PAHs (grey bars). PAH concentrations in food was $X$; the environmental reference concentrations corresponding to Xpy=17305 $\pm 4798 \mu \mathrm{g} . \mathrm{g}^{-1}$ and Xpe $=8082.5 \pm 305 \mu \mathrm{g} . \mathrm{g}^{-1}$ of dry food (table 1). Aerobic metabolic rate was estimated at two life stages: juvenile and adults. Results are expressed as mean values \pm standard deviation. For a given type of PAHs (PY or HO) and a given duration, * indicates a significant difference in AMR between control and X treatment.

In $D$. rerio which ingested $\mathrm{HO}$-PAH-contaminated food, the lack of SMR data for juveniles did not allow estimation of SMR and AMS for this stage. In adults, SMR did not differ significantly between control and contaminated fish (Fig. 2B; Student's t-test: dof $=27$ and $p$ $=0.35)$. On the contrary, AMR was significantly impaired, but only in adults (Student's t-test: dof $=20$ and $p=0.43$, dof $=27$ and $p=0.006$, for juveniles and adults, respectively; Fig. 2B),

314 as was AMS (Student's t-test: dof $=27$ and $p=0.003$ ). 
318 During histopathological examination, no anomalies were observed in skeletal muscle for 319 either $P Y$ - or $H O$-PAH exposure. While no heart damage was observed for $P Y$-PAH exposure, 3204 out of 25 fish exposed to $\mathrm{HO}$-PAH for 7 months displayed generalized oedema that severely 321 thickened the peritoneum all around the abdominal cavity. Significant heart impairments were 322 associated with this oedema: the pericardium appeared dilated with fluid and the heart was very small and rounded with a thin ventricular wall (Fig. 3; chi-square test, dof $=1$ and $p=$ 0.002). These lesions are characteristic of cardiac insufficiency with secondary collection of fluid in connective tissue and body cavities.
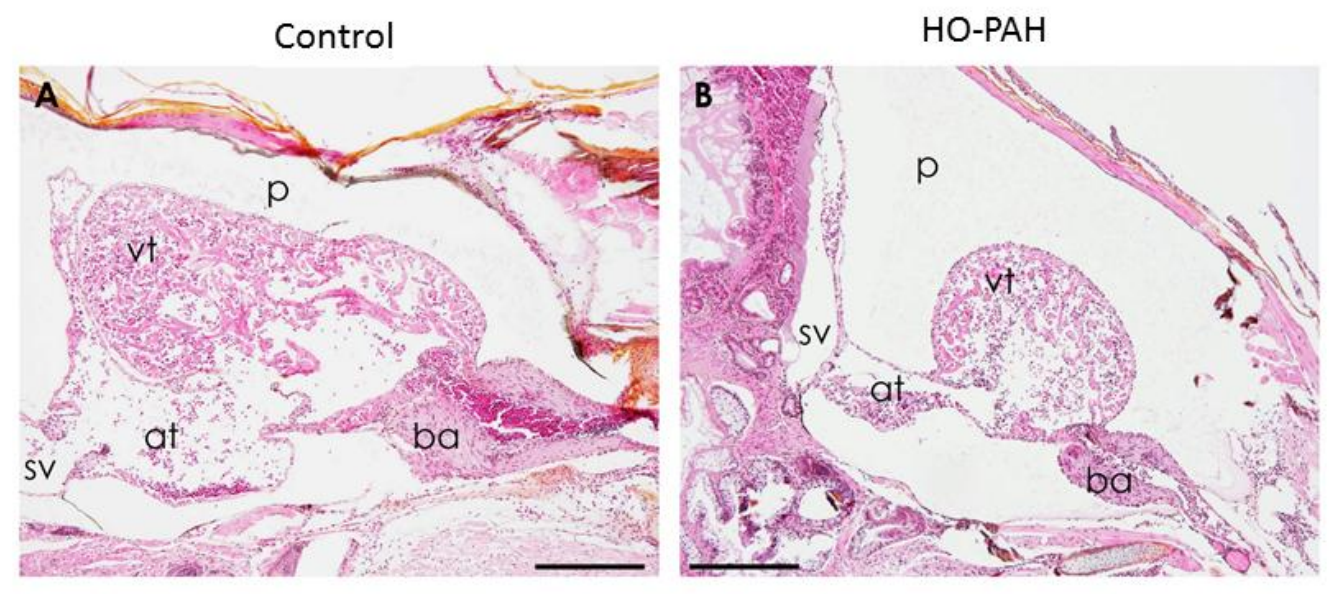

Fig. 3 Heart of zebrafish exposed to control condition of food (A) or to PAHs from petrogenic origin (B). Compared to a control fish, some fish exposed to PAHs displayed a large pericardial cavity with a small rounded heart. at: atrium; ba: bulbus arteriosus; p: pericardium; sv: sinus venosus; vt: ventricle. Hemalun-Eosin-Saffron. Bars $=200 \mu \mathrm{m}$. 


\section{Discussion}

335 Under these experimental conditions and at the two life stages tested, trophic exposure to 336 PAH differently impaired the fish depending on the type of PAH, i.e. PY or HO, and the 337 considered traits. AMR and $\mathrm{U}_{\text {crit }}$ were indeed influenced by HO-PAH, but SMR was not.

338 First, for a general comparison, swimming performance data were in the range of what other authors have observed in D. rerio, since average $\mathrm{U}_{\text {crit }}$ ranged between 10 and $16.5 \mathrm{BL} . \mathrm{s}^{-1}$ in

340 control individuals (e.g. $\mathrm{U}_{\text {crit }}=13 \mathrm{BL} \cdot \mathrm{s}^{-1}$ in Plaut and Gordon, 1994; $\mathrm{U}_{\text {crit }}=15.5 \mathrm{BL} \cdot \mathrm{s}^{-1}$ in 341 Plaut, 2001); $\mathrm{U}_{\text {crit }}=18$ BL.s ${ }^{-1}$ in Palstra et al., 2010).

342 AMR values in control fish ranged between 0.9 and $1.6 \mathrm{mg} \mathrm{O}_{2} \cdot \mathrm{h}^{-1} \cdot \mathrm{kg}^{-1}$, i.e. 30 to 60 lower 343 compared with other studies in the same species (Thomas and Janz, 2011, Lucas et al., 2014a, 344 2016). Such differences observed in AMR estimation could be explained by differences in the 345 general physiological status of the tested zebrafish (e.g. related to age, thermal acclimatization, 346 rearing conditions), as well as in the protocols used. It is also worth noting that Peake and 347 Farrell (2006) underlined the importance of behavioural regulations in assessing fish 348 performance through swimming challenges. They suggested that behaviour, rather than 349 physiological exhaustion, participates in the fatigue observed in fish tested in a swim flume, 350 thereby increasing the variability of the measured parameters (i.e. AMR and $U_{\text {crit }}$ ).

352 Focussing on contamination, HO-PAH exposure induced a significant decrease of 15 and $35326.5 \%$ of $\mathrm{U}_{\text {crit }}$ in zebrafish exposed for 2 and 6 months, respectively. A similar pattern was 354 observed in the literature regarding pollutant effects (Cheng and Farrell, 2007; Hicken et al., 355 2011; Howard, 1975; Marit and Weber, 2011, 2012; Thomas and Janz, 2011). In HO-PAH 356 adults, this was associated with a significant reduction of AMR, cardiac lesions (i.e. a smaller 
and more rounded heart with a thin ventricular wall), generalized oedema and collection of

358 fluid in body cavities indicating a functional cardiac insufficiency. These lesions may induce a

359 reduction of cardiac performance and capacity to transport oxygen. This may limit aerobic 360 metabolism, especially during high levels of activity, such as occurs during swimming (Farrell 361 1997, 2007; Fry, 1947, 1971; Claireaux et al., 2005; Priede, 1985).

362 Even if $\mathrm{U}_{\text {crit }}$ was reduced in HO-PAH juveniles, no impairment of AMR or cardiac function 363 was observed. It is worth noting that $\mathrm{U}_{\text {crit }}$ depends on both aerobic and anaerobic metabolism 364 (Webb, 1998), which could explain the results observed. However, the anaerobic part of the metabolism required to attain $\mathrm{U}_{\text {crit }}$ was not assessed in the present study, nor was oxygen debt after the swimming test (e.g. Vagner et al., 2008). Indeed, it would have been interesting to assess whether reduction of Ucrit was associated to a different sollicitation of anaerobic metabolism in juveniles and adults'

Contrary to the HO-PAH mixture, exposure to PY-PAH did not impair fish metabolic and swimming performance or cardiac anatomy. The lack of effect could be explained by the fact

372 that organisms that suffer long-term chronic environmental stress can present physiological 373 adaptations to maintain their homeostasis. Chronic exposure to PY-PAH may have induced such adaptations in D. rerio.

375 Whatever the type of exposure, no effect was observed on SMR. The range of observed 376 values are in agreement with previous studies carried out for the same species and with a 377 similar experimental approach $\left(\mathrm{SMR}=0.19 \mathrm{mg} \mathrm{O} \cdot \mathrm{g}^{-1} \cdot \mathrm{h}^{-1}\right.$ in Barrionuevo and Burggren, 378 1999; mean \pm s.d., $\mathrm{SMR}=0.31 \pm 0.11$ and $0.35 \pm 0.16 \mathrm{mg} \mathrm{O}_{2} \cdot \mathrm{g}^{-1} \cdot \mathrm{h}^{-1}$ in juveniles and adults, 379 respectively, in Lucas et al., 2014a, 2016).

380 Even though the concentration of PAH and their metabolite compounds was not assessed in 381 juveniles and adults in this study, they were estimated in 15 dpf larvae exposed to HO- or PY- 
382 PAH, and ranged between $42 \mathrm{ng} \cdot \mathrm{g}^{-1}$ and $136 \mathrm{ng} \cdot \mathrm{g}^{-1}$, respectively (Vignet et al., 2014).

384 It is likely that PAH metabolite concentration increased proportionally with the duration of 385 exposure. However, the present results suggest that the level of contamination tested was not 386 sufficiently extreme to induce significant variation in SMR in our experimental conditions., 387 PAH exposure did not induce supplementary costs of maintenance due to detoxification 388 processes in zebrafish (Lannig et al., 2006; Lucas et al., 2016; Sokolova and Lannig, 2008; 389 Wilson et al., 1994), which is contrary to one of the initial hypotheses.

390 The different impairment of the types of PAH mixture the fish were exposed to could be 391 explained by their different chemical properties depending on the composition of individual 392 PAH (Vignet et al., 2014). It is worth noting that toxicity depends on individual intrinsic 393 properties of each component and their interactions with enzymatic systems in organisms. 394 Mainly characterized by four- to six-ring PAH and 5\% of methylated compounds, PY-PAH 395 could induce less toxic effects than HO-PAH despite its higher concentration (Table 1). 396 Indeed, HO-PAH mixtures were characterized by three- and four-ring PAH, and $47 \%$ of 397 methylated compounds, which are considered to be more toxic for organisms (Di Giulio and 398 Hinton, 2008; Hall and Oris, 1991; Hylland, 2006; Tuvikene, 1995). In addition, adults that 399 were exposed to PAH for 6 months were therefore expected to contain more PAH metabolites 400 than juveniles, which coped with PAH exposure for only 2 months. This may contribute to the 401 fact that exposure to HO-PAH induced a significant reduction of AMR in adults and not in 402 juveniles. However, this pattern was not observed in juveniles and adults exposed to PY-PAH 403 (Fig. 1B) as well as in the similar study of Lucas et al. (2016).

404

405

\section{Conclusion}


408 Our results suggest that, contrary to HO-PAH, PY-PAH have no direct effect on aerobic 409 metabolism and swimming performance. Lucas et al. (2014b) have observed impairment of 410 metabolic performance and cardiac activity on the progeny of PY-PAH-contaminated D. rerio 411 parents. The parental effect of PAH exposure appears to be an important subject to study.

412 This study on swimming performance and associated energetic costs will be completed by 413 investigations regarding escape performance. This type of swimming depends on anaerobic 414 metabolism, as well as on sensorial and locomotion performance. Moreover, interfering with 415 some physiological mechanisms, PAH could be narcotic, inducing lethargic behaviour and 416 impairing the swimming performance of fish (Wassenberg and Di Giulio, 2004). All these 417 studies will permit a global view of the impact of this type of trophic contamination across 418 zebrafish generations.

\section{Acknowledgements}

The authors are grateful to Didier Leguay and Michel Prineau for their help during the

422 experiment. All experiments were carried out at Ifremer (Plateforme d'Ecophysiologie des 423 Poissons), La Rochelle station, France. This study was financially supported by the ANR 424 project ConPhyPoP (CES 09_002) and JL received a doctoral grant from the Regional 425 Council of Poitou-Charentes. This study was conducted under the approval of the Animal 426 Care Committee of France under the official licence to Marie-Laure Bégout (17-010). 


\section{References}

431 Barrionuevo, W.R., Burggren. W.W., 1999. $\mathrm{O}_{2}$ consumption and heart rate in developing zebrafish (Danio rerio): influence of temperature and ambient $\mathrm{O}_{2}$. Am. J. Physiol. 276, 505-513.

Beamish, F.W.H., 1978. Swimming capacity, in: Hoar, W.S., Randall, D.J. (Eds.), Fish Physiology, Vol. 7. Academic Press, New York, London, pp. 101-187.

Blier, P.U., Pelletier, D., Dutil, J.D., 1997. Does aerobic capacity set a limit on fish growth rate? Rev. Fish. Sci. 5(4), 323-340.

Brett, J.R., 1964. The respiratory metabolism and swimming performance of young sockeye salmon. J. Fish. Res. Board Can. 21, 1183-1226.

Budzinski, H., Jones, I., Bellocq, J., Pierard, C., Garrigues, P., 1997. Evaluation of sediment contamination by polycyclic aromatic hydrocarbons in the Gironde estuary. Mar. Chem. 58, 85-97.

Bustamante, P., Luna-Acosta, A., Clemens, S., Cassi, R., Thomas-Guyon, H., Warnau, M. (2012). Bioaccumulation and metabolisation of 14C-pyrene by the Pacific oyster Crassostrea gigas exposed via seawater. Chem.87, 938-944.

Cachot, J., Geffard, O., Augagneur, S., Lacroix, S., Le Menach, K., Peluhet, L., Budzinski, H., 2006. Evidence of genotoxicity related to high PAH content of sediments in the upper part of the Seine estuary (Normandy, France). Aquat. Toxicol. 79, 257-267.

Cachot, J., Law, M., Pottier, D., Peluhet, L., Norris, M., Budzinski, H., Winn, R., 2007. Characterization of toxic effects of sediment-associated organic pollutants using the

452 Cailleaud, K., Forget-Leray, J., Souissi, S., Hilde, D., LeMenach, K., Budzinski, H., 2007. 453 Seasonal variations of hydrophobic organic contaminant concentrations in the water- 
column of the Seine Estuary and their transfer to a planktonic species Eurytemora affinis (Calanoida, copepoda). Part 1: PCBs and PAHs. Chemosphere 70(2), 270-280.

Cannas, M., Atzori, F., Rupsard, F., Bustamante, P., Loizeau, V., Lefrançois, C., 2013. PCB contamination does not alter aerobic metabolism and tolerance to hypoxia of juvenile sole (Solea solea). Aquat. Toxicol. 127, 54-60.

Cappello, T., Mauceri, A., Corsaro, C., Maisano, M., Parrino, V., Lo Paro, G., Messina, G., Fasulo, S., 2013. Impact of environmental pollution on caged mussels Mytilus galloprovincialis using NMR-based metabolomics. Mar. Pollut. Bull. 77, 132-139.

Cheng, W.W., Farrell, A.P., 2007. Acute and sublethal toxicities of rotenone in juvenile rainbow trout (Oncorhynchus mykiss): swimming performance and oxygen consumption. Arch. Environ. Contam. Toxicol. 52, 388-396.

Claireaux, G., McKenzie, D.J, Genge, A.G., Chatelier, A. Aubin, J., Farrell, A.P., 2005. Linking swimming performance, cardiac pumping ability and cardiac anatomy in rainbow trout. J. Exp. Biol. 208, 1775-1784.

Clark, T.D., Donaldson, M.R., Pieperhoff, S., Drenner, S.M., Lotto, A., Cooke, S.J., Hinch, S.G., Patterson, D.A., Farrell, A.P., 2012. Physiological benefits of being small in a changing world: responses of coho salmon (Oncorhynchus kisutch) to an acute thermal challenge and a simulated capture event. PLoS One 7, e39079.

Daouk, T., Larcher T., Roupsard, F., Lyphout, L., Rigaud, C., Ledevin, M., Loizeau, V., Cousin, X., 2011. Long-term food-exposure of zebrafish to PCB mixtures mimicking some environmental situations induces ovary pathology and impairs reproduction ability. Aquat. Toxicol. 105(3-4), 270-278.

Davoodi, F., Claireaux, G., 2007. Effects of exposure to petroleum hydrocarbons upon the metabolism of the common sole Solea solea. Mar. Pollut. Bull. 54, 928-934.

Diaz, R.J., 2001. Overview of hypoxia around the world. J. Environ. Qual. 30, 275-281. 
Diaz, R.J., Nestlerode, J., Diaz, M.L., 2004. A global perspective on the effects of eutrophication and hypoxia on aquatic biota, in: Rupp, G.L., White, M.D. (Eds.), Proceedings of the 7th International Symposium on Fish Physiology, Toxicology and Water Quality, Tallinn, Estonia, May 12-15, 2003. EPA 600/R-04/049, U.S. Environmental Protection Agency, Ecosystems Research Division, Athens, Georgia, pp. 1-33.

Drucker, E.G., Jensen, J.S., 1996. Pectoral fin locomotion in the striped surfperch. I. Kinematics effects of swimming speed and body size. J. Exp. Biol. 199, 2235-2242.

Farrell, A.P., 1997. Effects of temperature on cardiovascular performance, in: Wood, C.M., McDonald, D.G. (Eds.), Global Warming Implications for Freshwater and Marine Fish. S.E.B. Seminar Series 61. Cambridge University Press, Cambridge, pp. 135-153.

Farrell, A.P., 2007. Cardiorespiratory performance during prolonged swimming tests with salmonids: a perspective on temperature effects and potential analytical pitfalls. Philos. Trans. R. Soc., B 362, 2017-2030.

Fasulo, S., Maisano, M., Sperone, E., Mauceri, A., Bernabo, I., Cappello, T., D’Agata, A., Tripepi, S., Bruneli, E., 2012. Toxicity of Foroozan crude oil to ornate wrasse (Thalassoma pavo, Osteichthyes, Labridae): ultrastructure and cellular biomarkers. Ital. J. Zool. 79(2), 182-199.

Fry, F.E.J., 1947. The effects of the environment on animal activity. University of Toronto Studies in Biology Series 55, 1-62.

Fry, F.E.J., 1971. The effect of environmental factors on the physiology of fish, in: Hoar, W.S., Randall, D.J. (Eds.), Fish Physiology Vol. VI. Academic Press, New York, pp. 1-98.

Graham, J.B., Dewar, H., Lai, N.C., Lowell, W.R., Arce, S.M., 1990. Aspects of shark swimming performance determined using a large water tunnel. J. Exp. Biol. 151, 175192. 
Hall, T.A., Oris, J.T., 1991. Anthracene reduces reproductive potential and is maternally transferred during long-term exposure in fathead minnows. Aquat. Toxicol. 19, 249264.

Hammer, C., 1995. Fatigue and exercise tests with fish. Comp. Biochem. Physiol. 112, 1-20.

Hawkins, W.E., Walker, W.W., Overstreet, R.M., Lytle, J.S., Lytle, T.F., 1990. Carcinogenic effects of some polycyclic aromatic hydrocarbons on the Japanese medaka and guppy in waterborne exposures. Sci. Total Environ. 94(1-2), 155-167.

Hicken, C.E., Linbo, T.L., Baldwin, D.H., Willis, M.L., Myers, M.S., Holland, L., Incardona, J.P., 2011. Sub-lethal exposure to crude oil during embryonic development alters cardiac morphology and reduces aerobic capacity in adult fish. Proc. Natl. Acad. Sci. U. S. A. 108, 7086-7090.

Howard, T.E., 1975. Swimming performance of juvenile coho salmon (Oncorhynchus kisutch) exposed to bleached kraft pulpmill effluent. J. Fish. Res. Board Can. 32, 789-793.

Hylland, K., 2006. Polycyclic aromatic hydrocarbon (PAH) ecotoxicology in marine ecosystems. J. Toxicol. Environ. Health, Part A 69(1-2), 109-23.

Johansen, J.L., Jones, G.P., 2011. Increasing ocean temperature reduces the metabolic performance and swimming ability of coral reef damselfishes. Global Change Biol. 17, 2971-2979.

Jones, D.R., Kiceniuk, J.W., Bamford, O.S., 1974. Evaluation of the swimming performance of several fish species from the Mackenzie River. J. Fish. Res. Board Can. 31, 16411647.

Jourdan-Pineau, H., Dupont-Prinet, A., Claireaux, G., McKenzie, D.J., 2010. An investigation of metabolic prioritization in the European sea bass, Dicentrarchus labrax. Physiol. Biochem. Zool. 83, 68-77.

Lannig, G., Flores, J.F., Sokolova, I.M., 2006. Temperature-dependent stress response in 
oysters, Crassostrea virginica: pollution reduces temperature tolerance in oysters. Aquat. Toxicol. 79, 278-287.

Lawrence, C., 2007. The husbandry of zebrafish (Danio rerio): a review. Aquaculture 269, 120.

Lefrançois, C., Claireaux, G., 2003. Influence of ambient oxygenation and temperature on metabolic scope and scope for heart rate in the common sole Solea solea. Mar. Ecol.: Prog. Ser. 259, 273-284.

Lucas, J., Bonnieux, A., Lyphout, L., Cousin, X., Miramand, P., Lefrancois, C., 2016. Trophic contamination by pyrolytic polycyclic aromatic hydrocarbons does not affect aerobic metabolic scope in zebrafish Danio rerio. Ecotoxicol. Environ. Saf. 88, 433-442

Lucas, J., Schouman, A., Lyphout, L., Cousin, X., Lefrancois, C., 2014a. Allometric relationship between body mass and aerobic metabolism in zebrafish Danio rerio. $\mathrm{J}$. Fish Biol. 84(4), 1171-1178.

Lucas J., Perrichon P., Nouhaud M., Audras A., Le Menach, K., Budzinski H. , Lefrancois C. 2014b Aerobic metabolism and cardiac activity in the descendants of zebrafish exposed

Marit, J.S., Weber, L.P., 2011. Acute exposure to 2,4-dinitrophenol alters zebrafish swimming performance and whole body triglyceride levels. Comp. Biochem. Physiol., Part C: Toxicol. Pharmacol. 154, 14-18.

Marit, J.S., Weber, L.P., 2012. Persistent effects on adult swim performance and energetics in zebrafish developmentally exposed to 2,3,7,8-tetrachlorodibenzo-p-dioxin. Aquat.

552 Myers, M.S., Landah, J.T., Krahn, M.M., McCain, B.B., 1991. Related lesions and exposure to relationships between hepatic neoplasms toxic chemicals in marine fish from the U.S. 
O’Connor, T.P. \& Lauenstein, G.G. (2006). Trends in chemical concentrations in mussels and oysters collected along the US coast: update to 2003. Mar. Environ. Res. 62, 261-285.

Palstra, A.P., Tudorache, C., Rovira, M., Brittijn, S.A., Burgerhout, E., van den Thillart, G. E., Spaink, H.P., Planas, J.V., 2010. Establishing zebrafish as a novel exercise model: swimming economy, swimming-enhanced growth and muscle growth marker gene expression. PLoS One 5(12), e14483.

Payne, J.R., Driskell, W.B, Short, J.W., Larsen, M.L., 2008. Long term monitoring for oil in the Exxon Valdez spill region. Mar. Pollut. Bull. 56(12), 2067-2081.

Peake, S.J., Farrell, A.P., 2006. Fatigue is a behavioural response in respirometer confined smallmouth bass. J. Fish Biol. 68, 1742-1755.

Plaut, I., 2001. Critical swimming speed: its ecological relevance. Comp. Biochem. Physiol. 131, 41-50.

Plaut, I., Gordon, M.S., 1994. Swimming metabolism of wild-type and cloned zebrafish Brachydanio rerio. J. Exp. Biol. 194, 209-223.

Priede, I.G., 1985. Metabolic scope in fishes, in: Tytler, P., Calow, P. (Eds.), Fish Energetics: New Perspectives. Croom Helm, London and Sydney, pp. 33-63.

Reidy, S.P., Nelson, J.A., Tang, Y., Kerr, S.R., 1995. Postexercise metabolic rate in Atlantic cod (Gadus morhua) and its dependence upon the method of exhaustion. J. Fish Biol. 47, $377-386$.

Roche, D.G., Binning, S.A., Bosiger, Y., Johansen, J.L., Rummer, J.L., 2013. Finding the best estimates of metabolic rates in a coral reef fish. J. Exp. Biol. 216(11), 2103-2110. doi:10.1242/jeb.082925

Rome, L.C., 2007. The effect of temperature and thermal acclimation on the sustainable performance of swimming scup. Philos. Trans. R. Soc., B 362, 1995-2016. 
Schurmann, H., Steffensen, J.F., 1997. Effects of temperature, hypoxia and activity on the metabolism of juvenile Atlantic cod. J. Fish Biol. 50, 1166-1180.

Shingles, A., McKenzie, D.J., Taylor, E.W., Moretti, A., Butler, P.J., Ceradini, S., 2001. Effects of sublethal ammonia exposure on swimming performance in rainbow trout (Oncorhyncus mykiss). J. Exp. Biol. 204, 2691-2698.

Sokolova, I.M, Lannig, G., 2008. Interactive effects of metal pollution and temperature on metabolism in aquatic ectotherms: implications of global climate change. Clim. Res. 37, 181-201.

Steffensen, J.F. (1989). Some errors in respirometry of aquatic breathers: how to avoid and correct for them. Fish Physiol. Biochem.6, 49-59.

Stobutzki, I.C., Bellwood, D.R., 1994. An analysis of the sustained swimming abilities of preand post-settlement coral reef fishes. J. Exp. Biol. Ecol. 175, 275-286.

Swanson, C., Young, P.S., Cech, J.J., Jr., 1998. Swimming performance of Delta smelt: maximum performance, and behavioral and kinematic limitations on swimming at submaximal velocities. J. Exp. Biol. 201, 333-345.

Thomas, J.K., Janz, D.M., 2011. Dietary selenomethionine exposure in adult zebrafish alters swimming performance, energetics and the physiological stress response. Aquat. Toxicol. 102, 79-86.

Thomas, J.K., Wiseman, S., Giesy, J.P., Janz, D.M., 2013. Effects of chronic dietary selenomethionine exposure on repeat swimming performance, aerobic metabolism and methionine catabolism in adult zebrafish (Danio rerio). Aquat. Toxicol. 130-131, 112122.

Tuvikene, A., 1995. Responses of fish to polyclic aromatic hydrocarbons. Ann. Zool. Fenn. 32, 295-309.

Vagner, M., Lefrançois, C., Ferrari, R.S., Satta, A., Domenici, P., 2008. The effect of acute 
hypoxia on swimming stamina at optimal swimming speed in flathead grey mullet Mugil cephalus. Mar. Biol. 155, 183-190.

Vicquelin, L., Leray-Forget, J., Peluhet, L., LeMenach, K., Deflandre, B., Anschutz, P., Etcheber, H., Morin, B., Budzinski, H., Cachot, J., 2011. A new spiked sediment assay using embryos of the Japanese medaka specifically designed for a reliable toxicity assessment of hydrophobic chemicals. Aquat. Toxicol. 105, 235-245.

Videler, J.J., 1993. Fish Swimming. Chapman and Hall, London.

Vignet, C., LeMenach, K., Mazurais, D., Lucas, J., Perrichon, P., Le Bihanic, F., Lyphout, L., Frère, L., Bégout, M.-L., Zambonio-Infante, J.-L., Budzinski, H., Cousin, X., 2014. Chronic exposures to pyrolytic and petrogenic mixtures of PAHs through diet produce physiological disruptions in zebrafish - Part I: Survival and growth. Environ. Sci. Pollut. Res.

Waiwood, K.G., Beamish, F.W.H., 1978. Effects of copper, pH and hardness on the critical swimming performance of rainbow trout (Salmo gairdneri Richardson). Water Res. 12, $611-619$.

Walker, J.A., Ghalambor, C.K., Griset, O.L., McKenny, D., Reznick, D.N., 2005. Do faster starts increase the probability of evading predators? Funct. Ecol. 19(5), 808-815.

Wassenberg, D.M., Di Giulio, R.T., 2004. Synergistic embryotoxicity of polycyclic aromatic hydrocarbon aryl hydrocarbon receptor agonists with cytochrome P4501A inhibitors in Fundulus heteroclitus. Environ. Health Perspect. 112(17), 1658-1664. doi:10.1289/ehp.7168

Watkins, T.B., 1996. Predator-mediated selection on burst swimming performance in tadpoles of the Pacific tree frog, Pseudacris regilla. Physiol. Zool. 69, 154-167.

Webb, P.W., 1998. Swimming, in: Evans, D.H. (Ed.), The Physiology of Fishes. CRC Marine Science Series, New York, pp. 3-24. 
629 Wilson, R.W., Bergman, H.L., Wood, C.M., 1994. Metabolic costs and physiological 630 consequences of acclimation to aluminum in juvenile rainbow trout (Oncorhynchus 631 mykiss). 1: Acclimation specificity, resting physiology, feeding, and growth. Can. J. Fish. $632 \quad$ Aquat. Sci. 51, 527-535.

633

634 